Sowing the seeds of awareness

\section{David Streeter}

Green Inheritance.

By Anthony Huxley.

Collins-Harvill/Anchor-Doubleday:

1985. Pp. 193. £9.95, \$19.95.

Our Green and Living World: The

Wisdom to Save It.

By Edward S. Ayensu, Vernon H.

Heywood, Grenville L. Lucas and Robert A. Defilipps.

Cambridge University Press/Smithsonian Institution Press: 1984. Pp. 255. f12.95,

$\$ 24.95$.

In the Rain Forest.

By Catherine Caufield.

Heinemann/Knopf: 1985. Pp. 304.

f10.95, \$16.96.

ONE of the most striking features of current radio and television, in Britain at least, is the number of natural history programmes that are finding their way into the schedules. Radio 4 alone, for example, is currently putting out five such programmes a week. Until recently, however, wildlife was considered to consist wholly of animals; even in David Attenborough's celebrated television series Life on Earth, plants made a significant appearance in only one out of the thirteen parts.

David Bellamy's early programmes have done much to redress the balance and coincided with the emergence of a higher profile conservation movement drawing attention to, among other issues, the attrition of the tropical rain forests. The established conservation bodies began to take notice. In 1980 the Fauna Preservation Society symbolically changed its name to the Fauna and Flora Preservation Society, and in March 1984 the World Wildlife Fund and the International Union for the Conservation of Nature and Natural Resources launched an international programme for plant conservation. As part of this campaign, two books, both aimed primarily at the general market, have appeared almost simultaneously. Green Inheritance is published as the official book of the World Wildlife Fund's Plants Campaign and is written by Anthony Huxley, a well-known writer and lecturer on plants. Our Green and Living World has an appropriately international authorship of an African, two Europeans and an American.

The purpose of both books is to arouse concern over the quite staggering rate of destruction of much of the Earth's natural vegetation and to point to the consequences. Inevitably one draws comparisons between the two. As a plea for plants the case put by Anthony Huxley is the more compelling. The factual material is wellresearched, and while there are lapses here and there when the subject becomes more physiological the text as a whole provides a fascinating and lucid account of mankind's relations with and dependence upon plants. Separate chapters deal with the role of plants as food, fuel, medicine and objects of beauty, as well as with the wider role of vegetation in atmospheric and soil processes. Accounts of the origins and spread of crop plants and the medicinal uses of plants are particularly good, the latter containing some quite astonishing information such as that on the uses or, more properly, abuses of the thornapple. Apart from Huxley's persuasive style, much of the success of Green Inheritance rests with its design. The combination of a continuous discursive text alongside short illustrated vignettes providing more detailed information works well, and the standard of graphics and art work is high.

Our Green and Living World covers much the same ground and overall, perhaps, is the more authoritative of the two. However, for the general reader it is likely that its message will be less compelling, the style sometimes being closer to that of an undergraduate text. Unlike Green Inheritance it includes eight chapters on different vegetation types from deserts to rain forests and from wetlands to oceans. It is also more comprehensive on the subjects of genetic conservation and under-exploited crops (the separate chap-

\section{Who cares?}

\section{Marian Dawkins}

Strategies of Being Female: Animal

Patterns, Human Choices.

By Evelyn Shaw and Joan Darling. Harvester/Walker: 1985. Pp. 164. $£ 12.95, \$ 14.95$.

IT WAS only in the last few pages of this book that I understood what the authors' purpose in writing it really was. Initially, I had thought it was going to be yet another polemic about the allegedly male-dominated sexist views of sociobiology in general and its treatment of sexual behaviour in particular. As I have never been able to understand this particular criticism of sociobiology (sociobiological emphasis on the evolutionary importance of female choice seeming, if anything, to overemphasize the role of females), I began the book by being somewhat out of sympathy with the authors. Some distinctly group selectionist phraseology - such as "reproducing in anticipation of the species' future" (p.32) and "the true biological reasons for having children [are] to assure the survival of the human species" (p.121) - only increased my antipathy.

But I was curious. How were the rampaging, promiscuous, initiative-taking females they cite from all corners of the animal kingdom going to be related to our ters on firewood and cellulose are particularly good). Like Green Inheritance, the production can only be described as lavish, some of the photographs being quite superb.

The overall lesson of the two books is clear, and in particular both focus attention on the devastation of the tropical rain forests. Five years ago the US National Academy of Sciences calculated that over 50 million acres were destroyed or seriously damaged each year and the UN's Food and Agricultural Organization estimated in 1981 that at present rates almost one-fifth of the world's remaining rain forest would have gone by the end of the century. Catherine Caufield's In the Rain Forest is a carefully researched collection of essays on various aspects of rain forest ecology, exploitation and destruction. Subjects range from the building of the town and dam of Tucurui in the Amazon basin to the discovery of quinine. Figures and statistics spill off the pages, and the value of the book is enhanced by good indexing, text notes and a comprehensive bibliography, but it is not - and does not pretend to be a textbook on rain forest ecology. For anyone unfamiliar with the rain forest this is undoubtedly a good read and an intentionally perturbing one.

David Streeter is a Reader in the School of Biological Sciences, University of Sussex.

own species, as promised in the introduction? Would promiscuous female fish or birds be used as a model for human beings? Would female hyenas, with their sham male genitalia, be held up as an example to us all?

Only in the last two chapters do Shaw and Darling argue that human females are in fact different from those of any other species. Females of other species may show a wide variety of sexual behaviour, but only human females can choose which particular one they will adopt for themselves. Looking after children is not, they argue, "biologically programmed in the genes of the female". "Words - not our hormones, and not some neurological Gestalt etched into our brains - teach us how to find a mate, who is appropriate as a mate and who isn't, when to have babies, how to give birth to them, and how to take care of them" (p.152). It is all the fault of culture, and the "myth of maternalism" in particular, that women are the ones most commonly adopting a child-caring role.

It is to attack this myth of maternalism - the claim that mothers are inherently better at caring for offspring than fathers - that turns out to be the book's main purpose. Men, it is argued, are just as good at looking after children as women are, if only they are given the chance. The trouble is they are so rarely given the chance. In a wide variety of cultures, women exclude men and refuse to allow them to be present at the birth of their own children. Shaw and 